\title{
THEORY OF ATTRACTIVE QUALITY
}

\section{Occupant satisfaction with indoor environmental quality at workplaces}

\author{
Quan Jin*, Holger Wallbaum, Jungsoo Kim, and Richard de Dear
}

\section{Background}

Satisfaction is dictionary-defined as the condition of having a desire or need to be fulfilled. The origin of the word can be backdated to eight centuries ago. The foundation for satisfaction lies in 'mankind's ability to learn' from previous experiences (Peyton \& Kamery, 2003). In the book Satisfaction, Oliver has provided a formal concept of satisfaction on the consumer perspective and elaborated that satisfaction is the fulfilment response and its pleasurable level of under- or over-fulfilment (Oliver, 1996). Satisfaction is a concept that has appeared in various disciplines, such as worker satisfaction in the industry, patient satisfaction in public health, and life satisfaction in sociology. Research on satisfaction generally sits upon a 'disconfirmation of expectation' theory; the feeling of satisfaction is formed through a cognitive process of comparing the perceived performance to expectations (Oliver, 1980). For instance, a perceived performance that exceeds expectations results in satisfaction (positive disconfirmation), whereas a performance below expectation results in dissatisfaction (negative disconfirmation).

One of the key features of satisfaction research is to understand the needs, identify and prioritise the determinants and optimise the process, since satisfaction reflects the emotion and behaviour which can be influenced by different attributes from the product or service. In 1984, Kano, Seraku, Takahashi, and Tsuji (1984) introduced the theory of attractive quality and the Kano model on product development and customer satisfaction, developed originally in the context of marketing. The theory has proposed two-dimensional quality as a relation between a subjective dimension of, for example, satisfaction and an objective dimension of, for example, physical attributes. For instance, the theory can be applied to study the relationship between customer satisfaction and product quality, or between employee satisfaction and job-related factors. The theory explains different relations between the satisfaction and the degree of fulfilment of a function with various quality attributes. In other words, it explicates when a quality attribute fulfils the function or fails to function, how it influences satisfaction and what categories the influence can be classified into. Traditionally, in the one-dimensional model, the level of satisfaction is assumed to be linearly correlated with product quality, that is, the better the quality,

*Corresponding author: quan.jin@chalmers.se 
the higher level the satisfaction. In contrast with the one-dimensional model, Kano's theory of attractive quality addresses the limitation by considering the non-linear and asymmetric relation between various quality attributes.

Therefore, the Kano model, which provides a bridge for putting the theory into practice, classifies customer preferences into five categories: must-be quality, one-dimensional quality, attractive quality, indifferent quality and reverse quality (Kano et al., 1984; Löfgren, Witell, \& Gustafsson, 2011). Figure 13.1 gives a general review of the Kano model and illustrates the five categories. It is based on recognising the feelings to be satisfied, dissatisfied or indifferent. The attractive quality of the first category contains the factors that have the highest and non-linear impact on satisfaction. It explains that the more the function is fulfilled, the greater the satisfaction is. However, it does not necessarily cause dissatisfaction when not fulfilled. The second category refers to the factors with one-dimensional quality. As was anticipated, satisfaction is linearly dependent upon these factors so that with the increase of fulfilment of the function, the satisfaction is also increased, and vice versa. The third category is the must-be quality. The factors in this category have the highest and non-linear influence on dissatisfaction. The failure of the performance of the factors leads to dissatisfaction, but the achievement of fulfilment does not necessarily result in satisfaction. The fourth category is socalled reversal quality, which means that the insufficiency of fulfilment promotes satisfaction, and vice versa. It is the opposite of the one-dimensional quality. The last category is indifference quality. The performance of fulfilment with various quality attribute does not influence satisfaction or dissatisfaction.

Attribute quality also may change over time, as indicated in Figure 13.1. With the development of the product or service, one attribute can change from an attractive feature to a must-be feature (Kano, 2001). For example, when the earliest air conditioning technology was

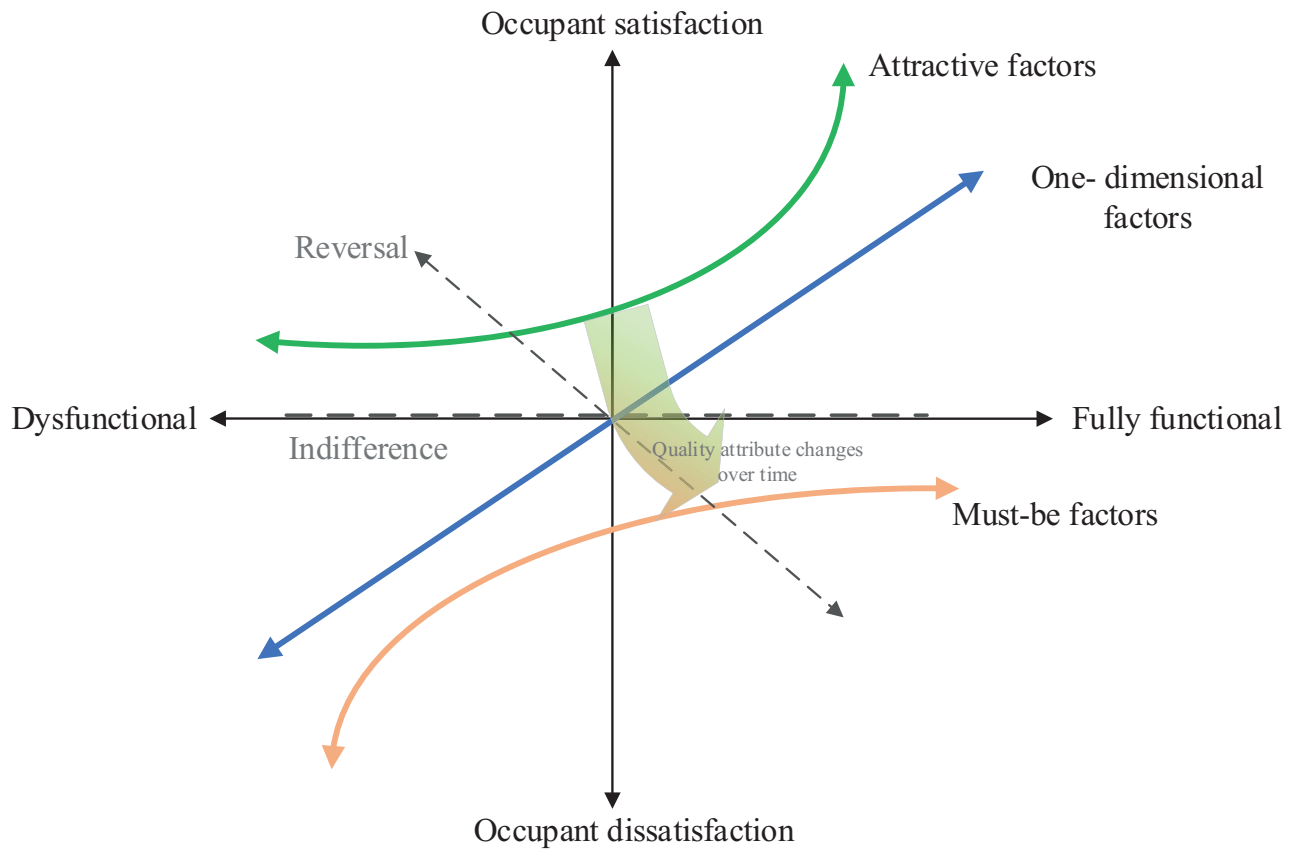

Figure 13.1 Kano's satisfaction model and categories of attribute quality (adapted from Kano et al., 1984) 
introduced in 1902, the air conditioner likely had an attractive quality. In modern society, an air conditioner has been widely implemented, and this attribute and the quality provided is perhaps assigned as a must-be or a one-dimensional quality.

During the past 20 years, the Kano theory and model has been increasingly utilised in different disciplines, from the traditional application in product development to other disciplines. For instance, the Kano model was integrated into the architectural design by suggesting subcategories for indifferent factors to better interpret various perceived design options (Ek \& Çıkış, 2015). The Kano model has also been applied in environmental quality science to clarify customer perceptions of an environmental attribute of a green product (Finster, Eagan, \& Hussey, 2001), such as packaging, recycling and energy consumption. The model has helped to create the incentives for environmental design and link to business value. In 2015, Luor, Lu, Chien and $\mathrm{Tu}$ further reviewed the Kano model in quality research by the publications from 1998 to 2012. It shows that the use of the Kano model has been increasing since 1998 as well as the times cited in academia. Thus far, the Kano model has been vastly applied in the four subject areas, including business economics, engineering, operation research management science and computer science. The Kano theory and model visualise the perceptions of a product, service or design and is of significance to identify the characteristics of various quality attributes. It triggers a continuous development of different disciplines to improve the concept and product by addressing and linking users' real needs.

\section{Application to workplaces}

Within the 17 UN Sustainable Development Goals (SDGs), Goal 3 on good health and wellbeing and Goal 8 on decent work and economic growth are closely related to the quality of indoor environments, where we spend more than $80 \%$ of our lives. This holds especially true for the millions of people working indoors. To achieve future positive and resilient workplaces, employees' needs and preferences should be put at the centre of building design, technology and service in terms of motivating and lifting their satisfaction to the environmental quality indoors.

\subsection{Occupant satisfaction with IEQ matters}

Indoor environmental quality (IEQ) simply refers to the quality of a building's environment. It should not only meet the basic needs of hygiene, physiology, sanitation and safety for the people who occupy the space but should also benefit occupant health and well-being. With the development of IEQ research over the past decades, there is growing awareness that IEQ is of high significance to guarantee a good quality of life and work for human beings and is one of the most significant aspects of concern in workplace design (World Green Building Council, 2014). IEQ is of major interest for occupants, employers and several other building-related stakeholders. It is commonly agreed that a comfortable and healthy indoor environment is vital for the well-being of occupants. A better IEQ reduces sick leave days and improves the productivity of employees (Fisk \& Rosenfeld, 1997). Research acknowledges that different factors of IEQ have direct effects on human comfort and health, and the direct links have been identified (Frontczak \& Wargocki, 2011; Wolkoff, 2013). Beyond comfort and health, the positive influence on the productivity of the occupants has also been reviewed and emphasised in green building research; for instance, the improved IEQ can lead to selfreported improvements in productivity (Singh, Syal, Grady, \& Korkmaz, 2010).

IEQ is a broad concept. The most important factors of IEQ for a building include thermal comfort, indoor air quality, acoustics and lighting (Buildings Performance Institute Europe, 
2018). The European standard EN 16798-1 also lists these IEQ factors and addresses building system design and energy performance. Apart from that, other non-environmental factors from architectural design and social perspective are also considered as part of IEQ and to be of significance for workplaces. These include office layout, view, colour, furnishings, cleanliness, maintenance and electromagnetic radiation (Malmqvist, 2008; Zagreus, Huizenga, Arens, \& Lehrer, 2004). Hence, when dealing with occupant satisfaction and expectation, which occurs through the relations among each of the IEQ factors, it becomes complex. Indeed, in real-life scenarios occupants would perceive the environment as a whole, making it extremely difficult to predict their attitude towards or their satisfaction with the building. Sometimes it is witnessed that poor IEQ does not necessarily harm occupant satisfaction, whereas on some other occasions an IEQ factor can trigger substantial criticism of a building. This gives us a hint that the significance of an IEQ factor can differ, depending on how it is perceived by an occupant.

\subsection{The Kano model for satisfaction research with IEQ}

Applying the Kano model to IEQ helps for better understanding the relationship between perceived building performance on specific indoor environmental factors and occupants' satisfaction with their workplaces. The Kano model of customer satisfaction is adapted for its utilisation on the subject of building occupants' satisfaction. Bringing the Kano theory and model into academia and research has triggered many studies using the model in environmental quality, and indoor environmental quality is one of the main disciplines to which the model has been applied.

The Kano model has been used to evaluate occupant satisfaction with IEQ in office buildings (Kim \& de Dear, 2012). The result is based on 43,021 post-occupancy evaluation questionnaires in 351 office buildings with natural ventilation, mechanical ventilation or mix-mode, and IEQ factors are categorised into basic, proportional and bonus factors. This three-factor structure of satisfaction, typically termed as the Kano model in the literature, categorises different qualities according to the direction of their effect on satisfaction. This study shows the following. First, for the basic factors, it includes temperature, noise, amount of space, visual privacy, adjustability of furniture, colours and textures, and workspace cleanliness. These are expected and are thus regarded as minimum requirements. Being predominantly associated with dissatisfaction, good quality on these factors doesn't necessarily improve satisfaction. Instead, they can cause dissatisfaction if they are deficient in some way. Second, proportional factors, which can affect satisfaction both positively and negatively, consist of air quality, amount of light, visual comfort, sound privacy, ease of interaction, comfort of furnishing, building cleanliness and building maintenance. Third, no bonus IEQ factors were recognised from the study, but there might exist possible bonus factors as the study has not covered all IEQ factors, for example daylight and external view. Bonus factors are not expected normally. Being predominantly associated with satisfaction, they can have a strong positive effect once they are fulfilled.

The Kano model can be viewed as an efficient and potential method for IEQ assessment related to satisfaction. For example, it can converge towards environmental quality and sustainability by combining with social cognitive theory (Dace, Stibe, \& Timma, 2020). It has also been shown to be the most suitable method to measure user satisfaction with adaptive behaviour in the indoor environment in energy-efficient buildings and can assist the design to integrate users' needs (Shafaghat et al., 2016). 


\section{Methodology/research approach}

\subsection{Examples of data collection from employees}

Data collection in the real world is a key approach for exploring the relations and interactions between indoor environment and employees' feelings about the quality of a building for both new building construction and existing building renovation. By collecting data on employees satisfaction and expectation, the Kano theory and model could be effectively applied and verified to recognise the key attributes in building design, operation and management. In parallel, the challenge of collecting data with employees in the organisation should not be overlooked since it often brings up the issues of resources and efforts allocated as well as the collaboration with the management group. Hence, a qualified data collection method and frame are of true significance for utilising and verifying the Kano model.

\subsubsection{Post-occupancy evaluation}

Post-occupancy evaluation (POE) can be defined as a systematic process of evaluating buildings that have been occupied for a certain period, focusing on building occupants and their needs (Preiser, Rabinowitz, \& White, 1988). Throughout the process of POE, data collection is an essential prerequisite to the development of useful knowledge. There are varieties of ways to collect building performance data, and they each have their level of difficulty and effort (i.e., amount of time, resources and the depth of evaluation). Conducting an occupant survey is probably the most prevalent method of collecting building performance data that can be found in studies in various disciplines. Different forms of POE questionnaire are in use around the world, but probably the best-known questionnaires focusing on office IEQ satisfaction are BUS (building use studies) and CBE (Center for the Built Environment). In the UK, the BUS survey questionnaire was adopted by and evolved throughout the PROBE (post-occupancy review of buildings and their engineering) research project that started in 1995 (Cohen, Standeven, Bordass, \& Leaman, 2001). In addition to the basic IEQ questions, the BUS system also collects detailed information about general topics such as building management, image of building, occupant's perceived productivity and health. In the USA, the CBE questionnaire was developed by the Center for the Built Environment at the University of California, Berkeley, and has been collecting occupant responses since 2000 (Zagreus et al., 2004). As a web-based survey, the participants are invited to the survey by e-mail and the survey results can be viewed through an automated online reporting tool. Occupants' satisfaction with seven core IEQ aspects is assessed on a seven-point rating scale. Branching questions are activated whenever a respondent indicates dissatisfaction with a certain IEQ aspect, which allows further investigation into the source of dissatisfaction. The BUS and CBE are implemented in various green building rating tools across the globe and are widely used survey tools for IEQ evaluation in the commercial building sector. It is also worth noting that although POE via BUS and CBE might have been superseded by the questionnaires behind some recent certification systems, for example, the WELL V2 certification (WELL, 2020), scientific evidence is still a challenge.

\subsection{2 'Furbish SSO' user insight approach}

'Furbish SSO' refers to the approach and tool for a deep user insight into smart and sustainable offices (Cobaleda-Cordero, Rahe, Wallbaum, Jin, \& Forooraghi, 2017; Jin, Wallbaum, Rahe, \& Forooraghi, 2019). It is a holistic mixed-method approach to collect employees' needs and feedback on the inner quality of a building and service during its life cycle including planning, design, operation 


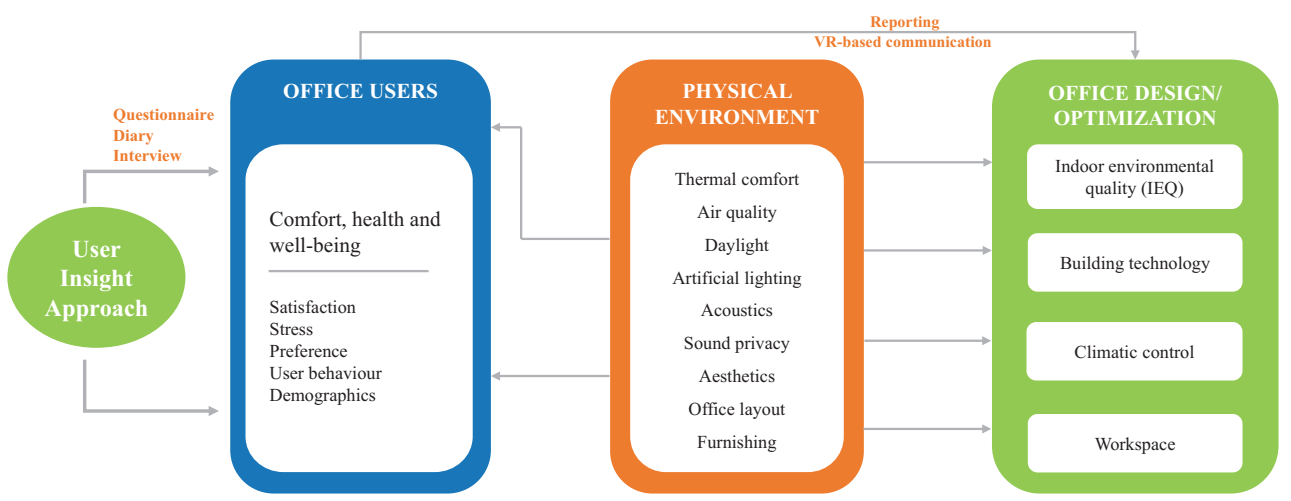

Figure 13.2 A mixed-method approach of qualitative and quantitative measures in smart and sustainable offices

and renovation. It aims to develop a strategy for the implementation of a new generation of useroriented and resilient building design solutions to provide empirical evidence for future office environments. One of the main focuses is to collect user experience and physical data on the specific indoor environment, including thermal comfort, air quality, daylight, lighting quality, acoustics, sound privacy, aesthetics, office layout and furnishings. Moreover, the social aspect is considered in this approach by assessing user demographics, user behaviour and energy use consciousness, as well as job-related satisfaction. The main components of the approach include a questionnaire, diary and focus group, as well as a number of individual interviews and a VR-based communication tool. The questionnaire maps a holistic picture of the user's general experience in the office environment, including satisfaction, stress and preference. The diary tracks the daily change of user satisfaction and behaviour, which allows the researchers to accurately relate the perceptions and measured physical environment. The semi-structured individual interviews and the focus-group interviews collect in-depth personal perspectives on the importance of the physical work environment characteristics and qualities in the office, along with the satisfaction with these characteristics and qualities. The VR tool supports a co-creation session with the users and planners to discuss and support indoor environmental design concepts following the preferences identified by applying the Furbish SSO approach. Based on the data collected of employees' perceptions of the office environment, the attractive features from a broad scope of physical work environment could be identified. Figure 13.2 shows the mixed-method approach with the main IEQ factors involved.

\subsection{Research gaps and the Kano model}

Attractive quality theory provides a way to explore the key features of satisfaction. Other theories also explain the origins of satisfaction, for instance users' satisfaction theories of assimilation theory (Festinger, 1957), contrast theory (Hovland, Harvey, \& Sherif, 1957) and negative theory (Anderson \& Fornell, 1994), which have been summarised by Aigbavboa and Thwala in 2013. However, comparing these theories, an advanced feature of the attractive theory includes the Kano model, which links the theory with practical use. The Kano model has been extensively used in marketing gaining perspective on customer satisfaction. Nevertheless, more applications to the studies in IEQ of building science are needed. Thus far, it is not sufficient for concluding which attractive key building attributes that employees value most at workplaces. Hence, the model should be applied to more populations and in various types of buildings and offices. 
As building technology and systems continue to develop, the model should address the dynamic nature of basic features, performance features and attractive features. Regarding the Kano model's function of specifying the attributes, for example to rank different attributes of the same quality for an overall evaluation of office satisfaction or to quantify the relation between each attribute and satisfaction, other methods of data mining could be further considered along with the Kano model, for example factor analysis, structural equation modelling, fuzzy modelling and Merenda and Gold's method (Bi, 2012; Dace et al., 2020; Gregory \& Parsa, 2013; Lee, Sheu, \& Tsou, 2008).

The attractive quality theory could be also further developed by verifying and testing in the real world. For example, coupling it with the empirical evidence gained from the IEQ field studies can help researchers and building professionals clarify the way to improve employees' satisfaction at workplaces. Aiming to shed light on the potential theory and model and to lift employees' satisfaction and achieve a sustainable working life in offices with high inner quality, in future research, subjective data need to be further aggregated at workplaces in different phases of a building's life cycle, especially with a longitudinal study enabling a critical test of pre-move and post-move to verify the Kano model on the key features of building attributes.

\section{Limitations}

A limitation of applying the Kano theory and model to workplaces in the field of IEQ exists in the possible bias of occupant perceptions of the building environment. The reliability and completeness of the subjective data collection and measurement cannot be neglected. Also, the influence of interactions between the various attributes on satisfaction is possibly lacking. The indoor environmental attributes are complex and relate to various aspects, including building physics, service engineering and building design. The relevant factors need to be holistically studied to identify key building attributes. More studies need to be conducted to verify the existing conclusions on potential quality categories. A limitation also exists in the further consideration of well-being at workplaces. For example, subjective perceptions of different environmental attributes with a focus on mental well-being have been measured by the Warwick-Edinburgh wellbeing scale (WARWICK, 2018). Concerns about the emotional responses on the health and mind and the economic impacts cannot be neglected either (see Chapter 14 Flourish Theory).

\section{Theory relevance to practice}

The application of the Kano model to the IEQ context indicates some IEQ factors' differential significance to occupant's overall environmental satisfaction. This has implications for those who operate a building, such as facilities managers. They must understand the relationship between occupant satisfaction and different IEQ factors before they make decisions for resource allocation. Those factors showing negative asymmetry (i.e., basic factors) such as 'thermal comfort' (Kim \& de Dear, 2012) will become more critical if they fail to meet occupant expectations, and even a substantial investment to improve a basic factor does not necessarily result in corresponding occupant satisfaction. Basic factors are regarded as 'must-have' elements, and therefore focusing on their negative aspects can be a strategic and a more efficient way to maintain occupant satisfaction to a certain level. In contrast, for those showing positive asymmetry (i.e., bonus factors) such as 'external view' (Kim \& de Dear, 2020) can be sources of occupants' delightful environmental experience, significantly contributing to enhancing overall satisfaction. Therefore, once basic factors have been delivered to a satisfactory level, it would be a rational strategy to focus on bonus factors to maximise occupant satisfaction. 


\section{Further reading}

- Clements-Croome, D. (Ed.). (2018). Creating the productive workplace: Places to work (3rd ed.). London: Routledge.

- Dace, E., Stibe, A., \& Timma, L. (2020). A holistic approach to manage environmental quality by using the Kano model and social cognitive theory. Corporate Social Responsibility and Environmental, 27, 430-443. https://doi.org/10.1002/csr.1828

- Kim, J., \& de Dear, R. (2012). Nonlinear relationships between individual IEQ factors and overall workspace satisfaction. Building and Environment, 49, 33-40. https://doi. org/10.1016/j.buildenv.2011.09.022

- Oliver, R. L. (1996). Satisfaction: A behavioral perspective on consumer. New York, NY: Prince Hill.

- Witell, L., Löfgren, M., \& Dahlgaard, J. J. (2013). Theory of attractive quality and the Kano methodology - The past, the present, and the future. Total Quality Management and Business Excellence, 24(11-12), 1241-1252. https://doi.org/10.1080/14783363.2013.791117

\section{References}

Aigbavboa, C., \& Thwala, W. (2013, December 17-18). A theoretical framework of users' satisfaction/ dissatisfaction theories [Paper presentation]. In 2nd international conference on arts, behavioral sciences and economics issues (ICABSEI'2013). Pattaya, Thailand. Retrieved from http://psrcentre.org/images/ extraimages $/ 12 \% 201213003 . p d f$

Anderson, E. W., \& Fornell, C. (1994). A customer satisfaction research prospectus. In R. T. Rust \& R. Oliver (Eds.), Service quality: new directions in theory and practice (pp. 241-268). Thousand Oaks, CA: SAGE Publications.

Bi, J. (2012). A review of statistical methods for determination of relative importance of correlated predictors and identification of drivers of consumer liking. Journal of Sensory Studies, 27(2), 87-101. https:// doi.org/10.1111/j.1745-459X.2012.00370.x

Buildings Performance Institute Europe (BPIE). (2018). The inner value of a building. Retrieved from http:// bpie.eu/wp-content/uploads/2018/10/The-Inner-value-of-a-building-Linking-IEQ-and-energyperformance-in-building-regulation_BPIE.pdf

Cobaleda-Cordero, A., Rahe, U., Wallbaum, H., Jin, Q., \& Forooraghi, M. (2017). Smart and Sustainable Offices (SSO): Showcasing a holistic approach to realise the next generation offices. Informes de la Construcción, 69(548), e221. https://doi.org/10.3989/id55278

Cohen, R., Standeven, M., Bordass, B., \& Leaman, A. (2001). Assessing building performance in use 1: The probe process. Building Research and Information, 29(2), 85-102. https://doi.org/10.1080/096132 10010008018

Dace, E., Stibe, A., \& Timma, L. (2020). A holistic approach to manage environmental quality by using the Kano model and social cognitive theory. Corporate Social Responsibility and Environmental Management, 27(2), 430-443. https://doi.org/10.1002/csr.1828

Ek, F. İ., \& Çıkış, Ş. (2015). Integrating the Kano model into architectural design: Quality measurement in mass-housing units. Total Quality Management and Business Excellence, 26(3-4), 400-414. https://doi. org/10.1080/14783363.2013.835898

Festinger, L. (1957). A theory of cognitive dissonance. Stanford, CA: Stanford Press.

Finster, M., Eagan, P., \& Hussey, D. (2001). Linking industrial ecology with business strategy: Creating value for green product design. Journal of Industrial Ecology, 5(3), 107-125. https://doi. org/10.1162/108819801760049495

Fisk, W. J., \& Rosenfeld, A. H. (1997). Estimates of improved productivity and health from better indoor environments. Indoor Air, 7(3), 158-172. https://doi.org/10.1111/j.1600-0668.1997.t01-1-00002.x

Frontczak, M., \& Wargocki, P. (2011). Literature survey on how different factors influence human comfort in indoor environments. Building and Environment, 46(4), 922-937. https://doi.org/10.1016/j. buildenv.2010.10.021

Gregory, A. M., \& Parsa, H. G. (2013). Kano's model: An integrative review of theory and applications to the field of hospitality and tourism. Journal of Hospitality Marketing and Management, 22(1), 25-46. https://doi.org/10.1080/19368623.2011.641073 
Hovland, C., Harvey. O., \& Sherif, M. (1957). Assimilation and contrast effects in reaction to communication and attitude change. Journal of Abnormal and Social Psychology, 55(7), 244-252. https://doi. org/10.1037/h0048480

Jin, Q., Wallbaum, H., Rahe, U., \& Forooraghi, M. (2019). SSO User Insight Toolbox for employees' health, well-being and productivity. REHVA Journal, 6, 58-63. Retrieved from www.rehva.eu/ rehva-journal/chapter/sso-user-insight-toolbox-for-employees-health-well-being-and-productivity

Kano, N. (2001, September 12-14). Life cycle and creation of attractive quality. In S. M. Park- Dahlgaard \& J. J. Dahlgaard (Eds.), Proceeding of the 4th international QMOD conference quality management and organizational development (pp. 18-36). Linköping, Sweden: Linköping University Electronic Press.

Kano, N., Seraku, N., Takahashi, F., \& Tsuji, S. (1984). Attractive quality and must be quality. Journal of the Japanese Society for Quality Control, 14(2), 147-156. https://doi.org/10.20684/quality.14.2_147

Kim, J., \& de Dear, R. (2012). Nonlinear relationships between individual IEQ factors and overall workspace satisfaction. Building and Environment, 49, 33-40. https://doi.org/10.1016/j.buildenv.2011.09.022

Kim, J., \& de Dear, R. (2020). Employee satisfaction and the quality of workplace environment. In O. B. Ayoko \& N. M. Ashkanasy (Eds.), Organizational behavior and the physical environment (pp. 13-36). London: Routledge.

Lee, Y. C., Sheu, L. C., \& Tsou, Y. G. (2008). Quality function deployment implementation based on Fuzzy Kano model: An application in PLM system. Computers and Industrial Engineering, 55(1), 48-63. https://doi.org/10.1016/j.cie.2007.11.014

Löfgren, M., Witell, L., \& Gustafsson, A. (2011). Theory of attractive quality and life cycles of quality attributes. The TQM Journal, 23(2), 235-246. https://doi.org/10.1108/17542731111110267

Luor, T., Lu, H. P., Chien, K. M., \& Tu, T. C. (2015). Contribution to quality research: A literature review of Kano's model from 1998 to 2012. Total Quality Management and Business Excellence, 26(3-4), $234-247$. https://doi.org/10.1080/14783363.2012.733264

Malmqvist, T. (2008). Environmental rating methods: Selecting indoor environmental quality (IEQ) aspects and indicators. Building Research E Information, 36(5), 466-485. https://doi.org/10.1080/ 09613210802075841

Oliver, R. L. (1980). A cognitive model of the antecedents and consequences of satisfaction decisions. Journal of Marketing Research, 17(4), 460-469. https://doi.org/10.1177/002224378001700405

Oliver, R. L. (1996). Satisfaction: A behavioral perspective on consumer. New York: Prince Hill.

Peyton, R. M., P. S., \& Kamery, R. H. (2003). Consumer Satisfaction/Dissatisfaction (CS/D): A review of the literature prior to the 1990s. Proceedings of the Academy of Organizational Culture, Communications and Conflict, 7(2), 41-46.

Preiser, W. F. E., Rabinowitz, H. Z., \& White, E. T. (1988). Post-occupancy evaluation. New York: Van Nostrand Reinhold.

Shafaghat, A., Keyvanfar, A., Muhd, M. Z., Lamit, H. B., Ahmad, M. H., Ferwati, M. S., \& Ghoshal, S. K. (2016). Methods for adaptive behaviors satisfaction assessment with energy efficient building design. Renewable and Sustainable Energy Reviews, 57, 250-259. https://doi.org/10.1016/j.rser.2015.12.133

Singh, A., Syal, M., Grady, S. C., \& Korkmaz, S. (2010). Effects of green buildings on employee health and productivity. American Journal of Public Health, 100(9), 1665-1668. https://doi.org/10.2105/ AJPH.2009.180687

WARWICK. (2018). The Warwick-Edinburgh Mental Wellbeing Scales - WEMWBS. Retrieved from https:// warwick.ac.uk/fac/sci/med/research/platform/wemwbs

WELL. (2020). WELL: Pre-approved programs. Retrieved from https://v2.wellcertified.com/resources/ preapproved-programs

Wolkoff, P. (2013). Indoor air pollutants in office environments: Assessment of comfort, health, and performance. International Journal of Hygiene and Environmental Health, 216(4), 371-394. https://doi. org/10.1016/j.ijheh.2012.08.001

World Green Building Council. (2014). Health, well-being \& productivity in offices: The next chapter for green building. Retrieved from www.worldgbc.org/news-media/health-wellbeing-and-productivityoffices-next-chapter-green-building

Zagreus, L, Huizenga, C, Arens, E, \& Lehrer, D. (2004). Listening to the occupants: A web-based indoor environmental quality survey. Indoor Air, 14(8), 65-74. https://doi.org/10.1111/j.1600-0668.2004.00301.x 